\title{
La autoridad en la Iglesia. Palabra y testimonio de Monseñor Romero
}

\author{
Miguel Cavada Diez, \\ Centro de Reflexión Teológica, \\ San Salvador.
}

Monseñor Romero ejerció la triple misión del obispo de enseñar, santificar y regir, tal como lo señala el Vaticano II en la Lumen Gentium, constitución dogmática sobre la Iglesia. Es bien conocido que enseñó de manera admirable a través de sus cartas pastorales y, sobre todo, de su predicación homilética(1). Pero no menos admirable fue su modo de regir, de gobernar la porción de la Iglesia que se le encomendo, de ejercer la autoridad.

Esto es lo que queremos analizar en este artículo, pero recordemos antes la difícil situación en que le tocó ejercer la autoridad y la decisión fundamental que hizo para Ilevar a cabo, cristianamente, tan diffcil misión. Monseñor Romero, en efecto, fue propuesto como arzobispo de San Salvador, porque, dado su pensamiento conservador, era el candidado ideal para garantizar la alianza entre el poder civil y eclesiástico. Pero los hechos fueron por otro lado y Monseñor Romero rompió esta alianza que no servia sino para legitimar la dominación de un grupo poderoso y excluyente. Y aún más, Monseñor Romero continú́ y llevó a su máxima expresión la tradición iniciada por Monseñor Chávez y Gonź́lez: puso el poder eclesial al servicio de los pobres. Con él, la Iglesia arquidiocesana se despojo de privilegios y ambiciones, e hizo consistir su poder en la debilidad de los pobres, que, al decir de Pablo, es "fuerza de Dios" (ICor 1, 17-29).

Esta ruptura con el poder civil y esta conversión a los pobres causó un doble efecto. Por una parte, el poder economico, político y militar se volvió contra la Iglesia y contra el mismo Monseñor Romero, desatando una persecución como

1. Cfr. M. Cavada Diez, "Predicación y profecla. Análisis de las homilias de Monseñor Romero", Revisto Latinoamericana de Teología 34 (1995), pp. 3-36. "La predicación como prolongación del proyecto salvifico de Cristo en las homillas de Monseñor Romero", ibid. 38 (1996), pp. 99-139. 
no se conocía en otras latitudes de América Latina. Por otra parte, la Iglesia arquidiocesana compartió la misma suerte y destino de los pobres(2), y ello hizo que ganara en autoridad y credibilidad. En este contexto de persecución a la Iglesia y de oposición a su propia autoridad episcopal, Monseñor Romero reflexionó en muchas de sus homilías sobre el tema de la autoridad.

A continuación queremos ofrecer una selección de textos de las homilías en los que Monseñor Romero nos enseña qué entiende por autoridad y cónto debe ejercerse. Para una mayor claridad, vamos a ordenar estos textos en dos apartados. En el primero agrupamos aquellos en que Monseñor Romero reflexiona sobre la autoridad y el poder: de dónde procede la autoridad, cuál debe ser la relación entre la autoridad de la Iglesia y la autoridad civil, cuál es el criterio para distinguir la verdadera y la falsa autoridad. En el segundo apartado agruparemos aquellos que reflejan el testimonio de Monseñor Romero como obispo de la arquidiócesis: cómo ejerció su carisma jerárquico y cuáles son las principales características de su ejercicio de la autoridad.

La doctrina y el ejercicio de autoridad de Monseñor Romero tienen un contexto muy preciso, como hemos dicho. Por eso he titulado los apartados con frases textuales de Monseñor Romero. Son frases bellas, evangélicas y polémicas, que de alguna manera resumen lo que fue fundamental en su palabra y su testimonio: distanciarse de los poderosos y aprender del pueblo.

\section{1. "No es un prestigio para la Iglesia estar bien con los poderosos"}

Es ya un tópico y una frase hecha afirmar que la autoridad es servicio, y el mismo Monseñor Romero se presentaba como el "humilde criado de la comunidad"(3). Que la autoridad es servicio es, pues, cosa que nadie en su sano juicio pone en duda, aunque luego la práctica esté muy lejos de dicho principio. Pero lo que ya no todos aceptan, ni siquiera en la teoría y mucho menos en la práctica, es que la autoridad debe estar al servicio de los pobres. A esto se podrá contestar que la autoridad debe estar al servicio de todos, sin distinción alguna, que hay que ejercer la autoridad con justicia y ecuanimidad, y este razonamiento no deja de tener validez. Pero a la luz del evangelio es incompleto. El evangelio de las bienaventuranzas no deja lugar a dudas: "el reino de Dios es para los pobres" (LC 6, 20).

Eso es el pensamiento central de Monseñor Romero, como veremos, pero antes ofrecemos un extenso párrafo de una de sus homilías(4), que nos introduce en lo central de su pensamiento sobre la autoridad:

2. Cfr. Homilla, 30 de junio de 1979 , VII, p. 37.

3. Cfr. Homilla, 23 de abril de 1978, IV, p. 189.

4. Cfr. "En Cristo se revelan las tres dimensiones de los verdaderos grandes", Homilfa, 23 de septiembre de 1979, VII, pp. 275-295. 
Si un hombre, por la necesidad de la sociedad, es elegido para ministro, para presidente de la república, para arzobispo, para servidor, es servidor del pueblo de Dios. ¡No hay que olvidarlo! La actitud que hay que tomar en esos cargos no es decir: "Yo mando aquí y se hace despóticamente lo que yo quiero". No eres más que un hombre ministro de Dios y tienes que estar pendiente de la mano del Señor para servir al pueblo según la voluntad de Dios y no según tu capricho. La voluntad de Dios es la que prevalece en el servicio de la autoridad. Cierto, muchos han querido echarnos en cara, como una subversión, que nosotros predicamos contra la autoridad. Nunca hemos predicado contra la autoridad verdadera. ¡Sí hemos predicado contra el abuso de la autoridad!

Cuando el Concilio Vaticano II, que ha vuelto a poner las cosas en su puesto, piensa en la jerarquía, nos dice a los obispos que ya no pretendamos ser los príncipes con los que se había prostituido la figura del obispo. No somos príncipes, no somos reyes. No hemos venido a ser servidos, sino que tiene que ser -he aqu! las palabras del Concilio-: "Los ministros que poseen la sacra potestad están al servicio de los hermanos". Yo soy el diácono de ustedes, queridos hermanos, soy el servidor, y toda la pastoral que deriva de la responsabilidad del pastor, tiene que ponerse toda en esta actitud de servicio: sacerdotes, religiosas, comunidades. Me alegra mucho -yo quiero decirlo con gran alegría-, que nuestra arquidiócesis va comprendiendo cada día mejor este sentido de servicio. Si acaso van quedando resabios de imperialismos, de potestad terrena, de paternalismo, yo les invito a todos: a los queridos sacerdotes, a las comunidades religiosas, a las superioras, a los superiores, que su papel no es sólo ser el jefe, sino el servidor de la comunidad, el que sabe escuchar los deseos y sabe orientarlos hacia Dios para servir a las necesidades del pueblo.

Cuando yo digo que soy el diácono, el servidor de ustedes, no quiero ser yo un acomodaticio para ganarme esos aplausos. De ninguna manera los he buscado yo. Ustedes me los han dado espontáneamente. Ni me envanecen, porque sé que no es más que la expresión de un pueblo que está sintiendo con aquel que les está dirigiendo la palabra y que está tratando de servirlo, precisamente, en sus sentimientos más hondos. Digo que no es oportunismo, sino que es más todavía, perdonen que les diga: No me interesa tanto la simpatía de ustedes como la simpatía de Dios. No me interesa tanto reinar sobre sus corazones -que gracias a Dios siento un cariño que me constituye casi rey de esta comunidad-, sino que me hace sentime, sobre todo, rey ante Dios. Servirlo es reinar y cuanto más humildemente lo quiera servir en el pueblo, más reinaré.

Por eso hay tanto malestar, porque no se ha comprendido la felicidad de ser humilde, porque no se ha comprendido la dicha de ser servidor, porque vamos 
discutiendo todavía por el camino quién es más grande aquf en la tierra, porque estamos haciendo consistir la alegría y el poder sólo en vanidades de la tierra. Ojalá se convirtieran, nos convirtiéramos todos los que tenemos cargos de autoridad para no creernos que por nuestra linda gracia estamos en el puesto alto, sino que estamos por voluntad de Dios. Que este Dios, que nos va a pedir cuenta a todos, hasta al más humilde, pedirá cuenta con más estrechez a aquel a quien le depositó la autoridad en sus manos para que la administrara según su corazón. ¡Ay de los poderosos, dice la Biblia, porque serán castigados más poderosamente por Dios! Podríamos seguir hablando de este aspecto, porque es bello. Y sería la lección más grande que aprenderíamos este domingo: ser humildes. Hacer consistir nuestra alegría en servir a Dios en la persona del pobre (Homilía, 23 de septiembre de 1979, VII, pp. 282-284).

La autoridad está, pues, sometida a la voluntad de Dios. Es "servir a Dios en la persona del pobre". La verdadera autoridad no es la que da órdenes y decretos, sino la que, antes de pronunciarse, sabe escuchar, recoger el consenso, la opinión, para orientarlo hacia Dios y servir a las necesidades del pueblo. La Iglesia, toda la Iglesia -subraya Monseñor Romero-, debe despojarse de los privilegios y dar signos claros de estar al servicio de Dios y no al servicio de los poderes de este mundo.

Cuando la autoridad está pendiente de la mano de Dios y de las necesidades del pueblo, entonces el pueblo agradece y aplaude, se siente protegido y defendido por un poder que es servicio. Monseñor Romero es consciente de que posee un poder. Su palabra tería un enorme poder de influencia. Todos, incluso sus enemigos, estaban pendientes cada domingo de lo que diría. Sin embargo, esto no lo envanece, sino que al contrario lo hace sentirse con más responsablilidad.

Apelar a Dios para justificar y legitimar el poder es práctica común en la historia de la humanidad. Monseñor Romero hace justamente lo contrario: en nombre de Dios desenmascara y denuncia los abusos del poder que, para mantenerse, pisotea los derechos de los pobres. En una homilia(5) donde el tema central de reflexión era precisamente la autoridad y el poder, afimna:

Cuando alguien absolutiza su poder y se erige idolo del poder y se vuelve contra las leyes de Dios, contra los derechos humanos, el atropello del pueblo, entonces no podemos decir que esa autoridad viene de Dios... La oración, el acercamiento a Dios, eso tiene que ser oficio de todo aquel que gobierna sea en lo civil como también en lo eclesiástico. Si un pastor, si un gobernante se aparta de Dios, no une con Dios su poder, entonces más que una fuerza

5. "Cristo, verdadero rey y pastor de todos los pueblos", Homilia, 22 de julio de 1979. VII, pp. 99-113. 
unitiva, como nos ha dicho el Concilio, se convierte en una fuerza de dispersión, y entonces en vez del bien se hace el mal (Homilia, 22 de julio de 1979, VII, pp. 109-110).

Cuando la autoridad olvida la opción por los pobres y quiere quedar bien con todo el mundo, ya no es servicio, es servilismo:

¿Para qué sirve una Iglesia, un cristianismo, cuando su predicación, su ejemplo se ha transtomado en un servilismo, en adulación, en quedar bien con todo el mundo? Sal insípida, luz apagada. ¡Qué fácil es estar bien con todo el mundo, pero qué ineficaz ser lámpara apagada! ¿Para qué sirve? (Homilía, 5 de febrero de 1978, II, p. 187).

Una autoridad que no se lundamenta en una clara, inequívoca y evangélica opción preferencial por los pobres difícilmente podrá ser reconocida como verdadera autoridad. No hay dudas de que Monseñor Romero se tomó en serio la opción preferencial por los pobres, que exige el evangelio y el magisterio de la Iglesia, particularmente Medellín y Puebla: "Hay que volver a encontrar la profunda verdad evangélica de que debemos servir a las mayorias pobres"(6).

Monseñor Romero introdujo la opción por los pobres como el criterio fundamental para definir las relaciones entre la Iglesia y el Estado. Monseñor Romero nunca buscó el enfrentarniento con el gobjerno, sino que fue el gobiemo quien buscó el enfrentamiento con el pueblo. $\mathrm{Y}$ ante ese dilema, Monseñor Romero optó por el pueblo:

No estoy confrontándome con nadie, sino que estoy tratando de servir al pueblo. Y el que esté en conflictos con el pueblo estará en conflictos conmigo. Pero mi amor es el pueblo. Y desde el pueblo pueden ver, a la luz de la fe y del mandato de Dios que me ha dado de conducir este pueblo por los caminos del evangelio, quiénes están conmigo y quiénes no están conmigo, viendo simplemente las relaciones del pueblo (Homilia, 20 de agosto de 1978, V, p. 134).

Fljense que el conflicto no es entre la Iglesia y el gobierno; es entre gobierno y pueblo. La Iglesia está con el pueblo y el pueblo está con la Iglesia. ¡Gracias a Dios! (Homilia, 21 de enero de 1979, VI, p. 137)(7).

La opción por los pobres exige tomar distancia del poder, sobre todo cuando éste oprime al pueblo. La Iglesia tendrá tanto más poder y credibilidad cuanto más distanciada esté de los poderosos y cuanto más cerca esté de los sufrimientos y esperanzas del pueblo pobre. La Iglesia tendrá tanto más poder cuanto más renuncie a los privilegios del poder. El texto de Monseñor Romero es claro:

6. Homilla, 2 de abril de 1978, IV, p. 133.

7. Cfr. Homilia, 21 de octubre de 1979, VII, p. 364. 
La lglesia animada por el Espíritu de Dios lleva la capacidad de la verdad. Queridos hermanos, llevar la capacidad de la verdad es sufrir el tormento interior que sufrían los profetas. Porque es mucho más fácil predicar la mentira, callar la verdad, acomodarse a las situaciones para no perder ventajas, para tener siempre amistades halagadoras, para tener poder. ¡Qué tentación más horrible la de la Iglesia! Y sin embargo ella, que ha recibido el Espíritu de la verdad, tiene que estar dispuesta a no traicionar la verdad. Y si es necesario perder todos los privilegios, los perderá, pero dirá siempre la verdad (Homilia. 22 de abril de 1979, VI, p. 313).

La Iglesia que comparte honores y privilegios con el poder político y económico cosecha su propio desprestigio y pierde autoridad moral(8). La autoridad de la Iglesia es permanecer fiel a la verdad: "más vale ser libre en la verdad que tener mucho dinero en la mentira"(9). La Iglesia debe presentarse "audazmente libre", 1omando clara distancia del "ídolo dinero" y del "ídolo poder". Monseñor Romero reconoce que esto está costando mucho en la Iglesia(10). La Iglesia no puede ser cómplice del poder que oprime a los pobres:

No podemos trabajar por quedar bien con los de arriba. Nuestra palabra en nombre de Dios tenemos que decirla denunciando tantas injusticias. ¡Hay tantas maneras de hacerse cómplice con las manos criminales! La Iglesia no puede complicarse con todo esto (Homilía, 15 de julio de 1979, VI, p. 81).

No es un prestigio para la Iglesia estar bien con los poderosos. Este es el prestigio de la Iglesia: sentir que los pobres la sienten como suya, sentir que la Iglesia vive una dimensión en la tierra llamando a todos, también a los ricos, a convertirse y a salvarse desde el mundo de los pobres, porque ellos son únicamente los bienaventurados (Homilia, 17 de febrero de1980, VII, p. 239).

Es un escándalo que haya personas e instituciones en la Iglesia que se despreocupan del pobre y viven a gusto (Homilía, 1 de julio de 1979, VII, p. 47).

La Iglesia no es ajena a la tentación del poder y el triunfalismo. Cuando la Iglesia hace consistir su poder en mantener buenas relaciones con los poderes de este mundo y en recibir ventajas de este poder, aunque sean bien intencionadas, se corre el peligro de traicionar la palabra de Dios, que es la única fuerza en la que se debe apoyar la Iglesia:

Obispos, sacerdotes, religiosos, instituciones católicas vamos a tener que sufrir esas tremendas tentaciones del poder. Vamos a querer convertir nuestra misión mesiánica salvadora en la humildad, en la austeridad, en el sacrificio y quererla

8. Cfr. Homilía, 6 de agosto de 1977, I-Il, p. 157.

9. Homilia 7 de mayo de 1978, IV, p. 210.

10. Cfr. Homilla, 15 de octubre de 1978, v, p. 249. 
apoyar en el poder, en el dinero, en el bienestar. ¡Cuántas veces ha cafdo la pobre Iglesia en estas tentaciones! De esto queremos salvar a la Iglesia auténtica. Que no haga consistir su prestigio en ser aplaudida, en ser apoyada por los triunfos fáciles. Queremos un cristianismo que de veras se apoye, como el de Cristo, en la palabra de Dios. Que no traicione, por más que la ofrezcan ventajas, la verdad de la palabra divina (Homilía, 12 de febrero de 1978, IV, p. 18).

\section{2. "El obispo siempre tiene que aprender mucho de su pueblo"}

Monseñor Romero dejó un gran ejemplo de cómo ejercer la autoridad dentro de la Iglesia. Su testimonio personal vale más que sus propias palabras. Nunca fue visto como un jefe, "como una autoridad que se impone", sino que fue recibido como el pastor que anima a la comunidad y el hermano que protege a los pobres, el amigo delpueblo(11):

Los obispos no mandamos con un sentido despótico. No debe ser así. El obispo es el más humilde servidor de la comunidad; porque Cristo lo dijo a los apóstoles, los primeros obispos: el que quiera ser más grande, hágase el más chiquito, sea el servidor de todos. Nuestro mandato es servicio. Nuestra conducción, nuestra palabra, es servicio (Homilia, 23 de abril de 1978, IV, pp. 188-189).

No soy un jefe, no soy un mandamás, no soy una autoridad que se impone. Quiero ser el servidor de Dios y de ustedes (Homilia, 10 de septiembre de 1978, V, p. 177).

Y precisamente porque Monseñor Romero fue el servidor de todos, no le gustaba el trato artificial y diplomático que confieren los títulos:

Ya decía santa Teresa de Jesús, ya nos confundimos qué título hay que darle a los prelados: si excelencia, si eminencia. $Y$ ni entendemos ya. Parecen payasadas muchas veces: ¡Excelencia, excelencia! ¡Cuánto más hermoso el nombre sencillo de cristiano! (Homilía, 5 de noviembre de 1978, V, p. 276).

Monseñor Romero fue una persona de diálogo. No se reconocía como el poseedor de la verdad absoluta. Al contrario, reconoce sus limitaciones y cree firmemente en el diálogo como el mejor mecanismo para ejercer la autoridad. Pero no sólo eso. Lo más novedoso y lo más importante es que Monseñor Romero se dejó ayudar por su pueblo y por sus colaboradores más cercanos. Su diario pastoral(12) da testimonio de las incontables entrevistas y conversaciones

11. En un conocido Ilamamiento a la oligarqura, se presenta ante ellos como "el pastor, el hermano y el amigo de este pueblo". Homilía, 6 de enero de 1980, VIII, p. 134.

12. Monseñor Oscar Amulfo Romero. Su diario. Del 31 de marzo de 1978 al 20 de marzo de 1980. Arzobispado de San Salvador, 1990. 
que sostuvo con diferentes personas. Después de un minucioso análisis de ese diario, acertadamente concluye Rodolfo Cardenal que Monseñor Romero fue "un hombre de diálogo"(13). Todas las estructuras de la arquidiócesis se convirtieron en medios para el diálogo, y un diálogo que tenía como objetivo no la imposición de una manera de pensar, sino la búsqueda sincera de la verdad sobre los hechos y la realidad del país.

Monseñor Romero mantuvo una permanente comunicación con su pueblo. Siempre estuvo rodeado de pobres, siempre estuvo cerca de los sufrimientos del pueblo. "El pastor tiene que estar donde está el sufrimiento", dijo en una ocasión(14). Cuando quiere tomar una decisión importante o decir una palabra trascendental para la vida del país, antes consulta al pueblo. De todos es conocido que, antes de redactar su Cuarta Carta Pastoral, consultó a las comunidades por medio de una encuesta(15). Al pueblo le pide que lea las homilías y le hagan llegar sugerencias(16). Sus homilías las preparaba con la ayuda de un equipo de colaboradores que le brindaban información y asesoría. Cuando una persona o un grupo no estuviera de acuerdo, pide encarecidamente que se dialogue con él(17). Y no se podrá argumentar que Monseñor Romero buscaba el diálogo solamente con personas que estaban en sintonía con su pensamiento. El citado diario pastoral da fe de que Monseñor Romero dialoga con personas de todos los sectores y de todas las ideologías.

Monseñor Romero es plenamente consciente de que la Iglesia es guiada y animada por el Espfritu de Jesús y no por los obispos. Estos deben estar atentos a los signos de los tiempos y los relos que la realidad histórica impone. En el lenguaje biblico esto se expresa mediante la imagen del fuego. La misión del obispo es atizar el fuego del Espíritu, es decir, animar nuevas iniciativas, abrir nuevos caminos, situar a la Iglesia en el servicio al mundo y de los que en el mundo ocupan el último lugar, la Iglesia al servicio del reino de Dios. El Espíritu siempre es creador, es el que hace nuevas las cosas y cosas nuevas, el que hace avanzar la Iglesia por los caminos de la historia. Sin embargo, muchos obispos en la Iglesia hacen justamente lo contrario: apagan el fuego del Espíritu. Esto significa involución y estancamiento. Entonces, la Iglesia se cierra en sí misma. Los obispos cometen la osadía de querer sustituir al Espíritu de Jesús, la autoridad se toma autoritarismo y hacen una Iglesia a su gusto y medida(18). Monseñor

13. R. Cardenal, "En fidelidad al evangelio y al pueblo salvadoreño. El diario pastoral de Moneñor Romero", Revista Latinoamericana de Teología 4 (1985) p. 36.

14. Homilia, 30 de oclubre de 1977, I-II, p. 296.

15. Cfr. numeral 7 de la Cuarıa Carta Pastoral de Monseñor Oscar A. Romero, Misión de la Iglesia en medio de la crisis del pais, 1979.

16. Cfr. Homilía, 13 de enero de 1980, VIII, p. 152.

17. Cfr. Homilia, 8 de mayo de 1977, I-II, p. 29.

18. Cfr. Homilía,7 de abril de 1977, J-1l, p.13. 
Romero fue plenamente consciente de que lo institucional en la Iglesia debe estar supeditado al Espíritu, y no al revés. La autoridad que no se somete al Espíritu es autoritarismo:

En la segunda lectura de hoy, hay tambien unos pensamientos que yo les voy a decir ahora con toda confianza de pastor con su pueblo. Son como las normas que quieren ser en mi pastoral lo que san Pablo dice a los tesalonicenses: "No apaguéis el Espíritu. No despreciéis el don de la profecla. Examinadlo todo, quedándoos con lo bueno". ¿Qué quiere decir esto: no extingáis el Espirilu Santo? Yo siento esta palabra, como obispo y pastor, con una tremenda responsabilidad. Porque yo sé que el Espíritu de Dios, que hizo el cuerpo de Cristo en las entrañas de María y sigue haciendo la Iglesia en la historia, aquf en la arquidiócesis, es un Espíritu que está -como dice el Génesis- aleteando sobre una nueva creación. Yo siento que hay algo nuevo en la arquidiócesis. Soy un hombre frágil, limitado, y no sé qué es lo que está pasando, pero sí sé que Dios lo sabe. Y mi papel como pastor es esto que dice hoy san Pablo: "No extingáis el Espíritu". Si con un sentido de autoritarismo yo le digo a un sacerdote: ¡No haga eso! $\mathrm{O}$ a una comunidad: ¡No vaya por allí! Y me quiero constituir como que yo fuera el Espíritu Santo y voy a hacer una Iglesia a mi gusto, estaría extinguiendo el Espíritu (Honilía, 17 de diciembre de 1978, VI, p. 47).

Y estar atento a la voz del Espíritu significa estar atento a la voz del pueblo pobre y creyente, el pueblo de Dios:

Quiero admirar y darle gracias al Señor porque en ustedes, pueblo de Dios, comunidades religiosas, comunidades eclesiales de base, gente humilde, campesinos, icuántos dones del Espíritu! Si yo fuera un celoso como los personajes del evangelio y de la primera lectura dira: ¡Prohlbasele, que no hable, que no diga nada, sólo yo obispo puedo hablar! ¡No! Yo lengo que escuchar qué dice el Espíritu por medio de su pueblo. Y entonces sf, recibir del pueblo y analizarlo, y junto con el pueblo, hacerlo construcción de la Iglesia. Así tenemos que construir nuestra Iglesia. Respetando el carisma jerárquico del que discierne, del que unifica, del que lleva a la unidad los diversos carismas variados. Y los jerarcas, los sacerdotes, respetando lo mucho que en el pueblo de Dios deposita el Espíritu (Homilia, 30 de septiembre de 1979, VII, p. 302).

En el último párrafo del texı que hemos citado, Monseñor Romero ubica correctamente el problema de la autoridad en la Iglesia. Se suele argumentar con mucha frecuencia que el pueblo de Dios debe estar en comunión con su obispo. Y dicho sea de paso, hasta la fecha no se conoce a ninguna comunidad cristiana que haya roto la comunión con su obispo. Hay sí comunidades que expresan su opinión al obispo, muchas veces una opinión discrepante, que emprenden nuevas iniciativas pastorales, que asumen un talante profético. Pero no llegan al extremo 
de romper la comunión eclesial. Y es que, como señala Monseñor Romero, la comunión tiene una doble dirección: es respeto del pueblo de Dios al carisma jerárquico y es, a la vez e inseparablemente, respeto de los obispos y sacerdotes a los carismas que el Espíritu entrega al pueblo.

Desgraciadamente no se toma en cuenta esto último con la misma insistencia que lo primero. Cuando se entiende y practica la comunión tal como la vivió y entendió Monseñor Romero, la autoridad es servicio y no autoritarismo. Monseñor abogó por un sano pluralismo en la Iglesia. La diversidad de voces y opiniones, lejos de ser una amenaza a la comunión de la Iglesia, la enriquecen y consolidan(19). A continuación citamos otro texto, donde Monseñor Romero repile el mismo argumento:

En esto se conoce un auténtico católico: en que está con su obispo. Si no está con su obispo no puede decirse buen católico. Eso no quiere decir que el obispo va a tener un despotismo: Hagan lo que yo digo. Porque precisamente el servicio que el obispo da está en función del pueblo. Precisamente en esa reunión que yo menciono de Cursillos de Cristiandad, hicimos una reflexión tan profunda que yo creo que el obispo siempre tiene mucho que aprender de su pueblo. Y precisamente, en los carismas que el Espíritu da al pueblo, el obispo encuentra la piedra de toque de su humildad y autenticidad (Homilía, 9 de septiembre de 1979, VI, pp. 245-246).

Si un buen católico es quien está con su obispo, también podemos afirmar que un buen obispo es quien está con su pueblo. Monseñor Romero expresaba que "con este pueblo no cuesta ser un buen pastor"(20). Podemos afirmar también lo contrario: con obispos como Monseñor Romero no cuesta ser cristiano. De eso se trata, de que el obispo ayude a su pueblo a ser pueblo de Dios.

Los obispos también deben convertirse. Esto es evidente, pero por eso mismo, se olvida con frecuencia. No es frecuente que los mismos obispos lo reconozcan públicamente y menos frecuente es que se refieran a los pobres como la piedra de toque de la autenticidad de su autoridad. Monseñor Romero en repetidas ocasiones hizo referencia a esta conversión de la Iglesia en general y de los obispos en particular. Citamos un ejemplo:

También los obispos, el Papa, todos los cristianos vivimos esta tensión, que Cristo dejó en el mundo, de conversión. ¡Y ay del pastor que no vive esta tensión, que se instala en una manera bonita de vivir! Nosotros tenemos que compartir con el pueblo la conversión. Y si gritamos contra el odio, contra la desunión, contra la calumnia, contra todas esas fuerzas infernales que dividen al mundo, tenemos que comenzar por nosotros mismos (Homilia, 22 de mayo de 1977 , I-II, p. 58).

19. Cfr. Homilia. 29 de mayo de 1977, I-11, p. 75.

20. Homilia, 18 de noviembre de 1979, VII, p. 445. 
Monseñor Romero es realista y afirma la posibilidad de obispos que no muestran en su ministerio el rostro amoroso del Padre, su voluntad salvífica. La misión de un obispo es ser signo de la presencia de Dios en el mundo:

No todos los miembros de la Iglesia, poseen e irradian a Dios... ¡Mucho cuidado, católicos! Comenzando por nosotros los ministros de Dios, no creamos que por ser obispos o sacerdotes, y por ser institución eclesiástica, somos lo mejor del cristianismo. Somos signo. Pero puede ser como la campana, que es signo y llama, pero se queda fuera. He aquí cómo Cristo también nos llama la atención a todos los que formamos esta institución, lo visible del cristianismo, para que tratemos de ser verdaderamente signos de una presencia de Dios en el mundo (Homilía, 13 de agosto de 1978, V, p. 125).

Monseñor Romero fue el buen pastor que caminó con el pueblo y defendí los derechos y la vida de los pobres. Una autoridad así es un estorbo para los poderosos. Monseñor Romero, como Jesús, fue amenazado a muerte en numerosas ocasiones, pero jamás retrocedió. Y en esto radica su mayor testimonio. Después de una de estas amenazas hizo pública esta promesa:

Quiero asegurarles a ustedes, y les pido oraciones para ser fiel a esta promesa, que no abandonaré a mi pueblo, sino que correré con él todos los riesgos que mi ministerio exige (Homilía, 11 de noviembre de 1979, VII, p. 432).

Cuando las autoridades, ante la insistencia y seriedad de las amenazas, le ofrecen seguridad, Monseñor Romero pronuncia las conocidas palabras, propias de un buen pastor, donde exige seguridad no para su persona, sino para su pueblo, amén de que Monseñor Romero es consciente de que mala seguridad le pueden ofrecer los principales responsables de la represión y la muerte contra el pueblo. Por eso, Monseñor Romero revierte el ofrecimiento y exige que el gobierno ofrezca seguridad a quien la debe ofrecer. Lo trágico del caso es que, unos días después de este ofrecimiento, las fuerzas de seguridad del Estado, asesinaron con lujo de barbarie al P. Octavio Ortiz y a cuatro jóvenes más:

Quiero agradecer las múltiples manifestaciones de solidaridad que me han llegado con motivo de lo que dije el domingo pasado, de cierta noticia de peligro contra mi vida. Yo no le quisiera dar más importancia a este asunto, porque estamos en las manos de Dios. Quiero agradecer lambién al seffor presidente de la república, desde luego, la atención de escuchar mis homilfas. Porque dicen que cuando los periodistas le preguntaron si sabia de esa amenaza, dijo que lo habla sabido por escucharlo en mi homilía. Muchas gracias, señor presidente, por escucharme. Pero también quiero agradecerle el haber ofrecido proporcionarme protección si yo se la solicitaba. Se lo agradezco, pero quiero repetir aquí mi posición: de que no busco yo nunca mis ventajas personales, sino que busco el bien de mis sacerdotes y de mi 
pueblo... Quiero decirle también, que antes de mi seguridad personal, yo quisiera seguridad y tranquilidad para 108 familias y desaparecidos, para todos los que sufren. Un bienestar personal, una seguridad de mi vida no me interesa mientras mire en mi pueblo un sistema económico, social y político que tiende cada vez más a abrir esas diferencias sociales (Homilia, 14 de enero de 1979, VI, pp. 121-122)(21).

A Monseñor Romero le paś lo mismo que a Jesús, no podía ser de otro modo. Quienes cuestionaron y negaron su autoridad e incluso intercedieron y maniobraron ante el Vaticano para exigir su destitución como obispo(22), fueron los ricos, los que hacen alarde de todo su poder. $Y$ quienes aceptaron gustosamente la autoridad de Monseñor Romero fueron los pobres de este pás, los que no tienen ningún poder, sino que, al contrario, son sometidos bajo el peso del abuso del poder.

Un obispo legítimamente consagrado es siempre la autoridad de una Iglesia local determinada, independientemente de cómo ejerza su misión. Pero a un obispo no le basta con ser legítimamente la autoridad de la Iglesia local, deberá ganarse la credibilidad de su pueblo. Entonces su autoridad será instrumento de salvación y no motivo de escándalo y desesperanza para el pueblo. Su autoridad será signo de la presencia de un Dios que camina con su pueblo.

\section{Conclusión}

Hay un paralelismo admirable entre la autoridad de Jesús(23) y la autoridad de Monseñor Romero. Sin lugar a dudas porque la autoridad tal como la entendí y ejerció Jesús fue la norma y el criterio fundamental que guió la práctica pastoral de Monseñor Romero.

La autoridad de Monseñor Romero no radica solamente en su condición de obispo, sino que su autoridad está sobre todo en su palabra y práctica profética. Monseñor Romero no necesitó la coerción ni otros medios semejantes para hacer sentir su autoridad, y no la necesito porque la verdad de su palabra y la coherencia de su testimonio convenclan y animaban a seguir sus pasos, a trabajar con él, aun a pesar del riesgo que eso traía consigo.

21. "Yo les quiero repetir lo que dije otra vez: El pastor no quiere seguridad mientras no le den seguridad a su rebaño", Homilla, 22 de julio de 1979, VII, p. 112.

22. "Estas firmas también piden mi destitución. Yo no tengo inconvenientes en ser destituido, ni tengo ambiciones en el poder de la diócesis. Simplemente considero que esto es un servicio, y que mientras el Serior, por medio del Ponúfice, me tenge en él, sere fiel a mi conciencia a la luz del evangelio, que es lo que yo trato de predicar, nj nada más ni nada menos", Homilia, 20 de agosto de 1978, V. p. 135.

23. Cfr. J. I. González Faus, "La autoridad de Jesús", Revista Latinoamericana de Teología 20 (1990), pp. 189-206. 
Monseñor Romero denunció el abuso de poder de las autoridades políticas, militares y económicas y denunció también el silencio y la alianza cómplice de una Iglesia desencarnada del mundo de los pobres. Monseñor Romero desenmascaró la absolutización e idolatrización del poder, una absolutización que llega el extremo del exterminio y el asesinato de las mayorías populares y de aquellos que optan por defender la vida y los derechos de los pobres. Este ejercicio profético de la autoridad uajo consigo el enfrentamiento y el conflicto con las autoridades mundanas. Al final de cuentas, el poder político no soportó a Monseñor Romero y terminó por asesinarlo.

Monseñor Romero "cambió lo que significa el poder institucional de la Iglesia"(24). Nos enseñó que el poder de la Iglesia no es simplemente estar al servicio de los pobres, sino que el poder de la Ílesia es dar la vida por los pobres: ser Iglesia de los pobres. La autoridad en la Iglesia se ejerce desde los pobres y con los pobres. En la medida que la Iglesia toma distancia de los poderes de este mundo, se despoja de privilegios, prebendas y ambiciones, y opta por los pobres, en esa medida la Iglesia gana autoridad y credibilidad ante el mundo y su mensaje se convierte en fuerza de liberación.

Monseñor Romero ejerció la autoridad mediante la cercanía y el diálogo con el pueblo de Dios y con el Dios que vive en medio de su pueblo. El diálogo con los pobres y con Dios fue la fuente y el criterio de su autoridad. Lo principal para Monseñor Romero no fue crear una relación de obediencia y sumisión hacia la autoridad eclesiástica, sino una relación de corresponsabilidad y libertad. Por eso, en su práctica pastoral, actúa más como un pastor que anima que como un administrador que vigila. Si con las autoridades polfticas civiles y religiosas fue el profeta que hizo sentir el poder de su palabra dura y exigente, con los pobres fue el pastor que animó, alentó y dio esperanza. Los pobres vieron en él un padre(25) y no un jefe.

Monseñor Romero, quizá sin pretenderlo, ejerció un nuevo estilo de ser obispo, que no fue otra cosa que la actualización de la imagen biblica del buen pastor (Jn 10, 11-17), que conoce a los suyos y los suyos lo conocen a él, que deliende la vida de los pobres a costa de ofrecer su propia vida. No es de extrantar que Monseñor Romero encontrara oposición dentro de la misma Iglesia y especialmente de aquellos que, con su testimonio, se vieron denunciados y cuestionados, sus hermanos los obispos.

En resumen, con su práctica profética y pastoral Monsefior Romero realizó y nos enseñó lo fundamental: que el objeto del poder no es ouro que revelar el

24. J. Sobrino, "Monseñor Romero márir de la liberación" en La voz de los sin voz. La palabra viva de Monseñor Romero, San Salvador, 1980, pp. 50-51.

25. Cfr. Homilia, 31 de diciembre de 1978, VI, p. 91. 
rostro misericordioso del Padre, el Dios de la vida. Como afirma González Faus, "los poderes que los hombres podamos tener están sólo para transparentar en su ejercicio el ser de Dios, pero nunca para apropiarse de Dios ni siquiera con la excusa de defenderlo"(26). Monseñor Romero ocupó un cargo de poder en la Iglesia, y, a la vez, su palabra tuvo una enorme influencia en la vida política de El Salvador. A través de ese poder, Monseñor Romero hizo presente, actual y cercano el amor y la misericordia de Dios.

26. Op. cir. p. 195. 